\title{
Predictive models to determine the behavior of plastic and liquid limit of Lateratic soil for Raod construction at Egbema: Imo state of Nigeria
}

\author{
Eluozo, S. $\mathbf{N}^{* 1}$, Nwaobakata, . $^{2}$ \\ ${ }^{I}$ Department of Civil Engineering, Faculty of Engineering, University of Nigeria, Nsukka \\ ${ }^{2}$ Department of Civil and Environmental Engineering, Faculty of Engineering, University of Port \\ Harcourt, Port Harcourt, Rivers State, Nigeria \\ *Corresponding author E-mail: solomoneluozo2000@yahoo.com
}

\begin{abstract}
Predictive model to determine the behaviour of plastic and liquid limit of lateritic soil for road design and construction has been developed, these two parameters have a relationship in terms of soil classification through their laboratory results, both parameters sample were subjected to thorough laboratory analysis for several locations, the laboratory results of both parameters were plotted to determine their behaviors and limits. The results generated equations at various locations, the equations were resolved and they generated theoretical values, the model values displayed their relationship on the classification of soil for road construction. The implementation of a laboratory testing procedure is to classify subgrade material and assess sustained properties and moisture sensitivity (heave, collapse, softening) that can influence long-term pavement performance. Testing implementation consists of classification testing, which are (i.e., gradation analysis, Atterberg Limits and sulfate tests). It also generated predictive models, producing theoretical values, other analysis are engineering properties testing (i.e., swell/consolidation, R-value, unconfined compressive strength, California Bearing Ratio, and Resilient Modulus Tests). These are also design parameters that should generate predictive models that can be applied as design parameter in the study area, the study is imperative because predictive models generated and validated has ascertained proof its workability as a parameter in the design of flexible pavements in the study location.
\end{abstract}

Keywords: predictive model, plastic and liquid limit, lateritic soil, Egbema Imo State of Nigeria.

\section{Introduction}

Over the years engineers have tried diverse methods to stabilize soils that are subject to fluctuations in strength and rigidity properties as a function of vacillation in moisture content. Stabilization can be derived from thermal, electrical, mechanical or chemical means. The first two options are rarely used. Mechanical stabilization, or compaction, is the densification of soil by application of mechanical energy. Densification occurs as air is expelled from soil voids without much change in water content. This method is particularly effective for cohesion less soils where compaction energy can cause particle reorganization and particle interlocking. But, the method may not be effective if these soils are subjected to important moisture fluctuations. The efficacy of compaction may also reduce with an increase of the fine content, fraction smaller than about $75 \mu \mathrm{m}$, of the soil. This is because cohesion and inter particle bonding interferes with particle rearrangement during compaction. Altering the physico-chemical properties of fine-grained soils by means of chemical stabilizers/modifiers is a more effective form of durable stabilization than densification in these finegrained soils. Substance stabilization of non-cohesive, coarse grained soils, soils with greater than 50 percent by weight coarser than $75 \mu \mathrm{m}$ is also beneficial if a substantial stabilization reaction can be achieved in these soils. In this case the strength improvement can be much higher, greater than ten fold, when compared to the strength of the untreated material. This report discusses key factors associated with stabilizing soils using chemical modifiers including: The soil must first be classified as either a subgrade category or base category material. In order to be classified as a base material the following criteria must be met: (1) a maximum of 25 percent of the soil mass passes the No. 200 sieve ( $0.074 \mathrm{~mm}$ or $0.003 \mathrm{in}$.$) , (2) not more than 40$ percent of the soil mass passes the No. 40 sieve $(0.42 \mathrm{~mm}$ or $0.0165 \mathrm{in}$.), (3) a maximum plasticity index of 12 percent, and (4) a maximum liquid limit of 40 percent. Otherwise, it is classified 
as a subgrade material for stabilization purposes. The definition of modification and stabilization can be ambiguous. In this document modification refers soil improvement that occurs in the short term, during or shortly after mixing (within hours). This modification reduces the plasticity of the soil (improves the consistency) to the desired level and improves short-term strength to the desired level (short-term is defined as strength derived immediately within about 7-days of after compaction). Even if no significant pozzolanic or cementitious reaction occurs, the textural changes that accompany consistency improvements normally result in measurable strength improvement. Stabilization occurs when a significant, longer-term reaction takes place. This longer-term reaction can be due to hydration of calcium-silicates and/or calcium aluminates in Portland cement or class $\mathrm{C}$ fly ash or due to pozzolanic reactivity between free lime and soil pozzolans or added pozzolans. A strength increase of $50 \mathrm{psi}(350 \mathrm{kPa})$ or greater (of the stabilized soil strength compared to the untreated soil strength under the same conditions of compaction and cure) is a reasonable criterion for stabilization. Construction steps in the stabilization process are not addressed in this document or in the Standard Practice associated with this document it permeate through soil voids [1]. Where the soil and stabilizing agent are blended and worked together, the placement process usually includes compaction. Oil stabilizing additives are used to improve the properties of less-desirable rood soils. When used these stabilizing agents can improve and maintain soil moisture content, increase soil particle cohesion and serve as cementing and water proofing agents [2]. A difficult problem in civil engineering works exists when the sub-grade is found to be clay soil. Soils having high clay content have the tendency to swell when their moisture content is allowed to increase [3]. Many research have been done on the subject of soil stabilization using various additives, the most common methods of soil stabilization of clay soils in pavement work are cement and lime stabilization. The high strengths obtained from cement and lime stabilization may not always be required, however, and there is justification for seeking cheaper additives which may be used to alter the soil properties. Lateritic soils are widely used as fill materials for various construction works in most tropical countries. These soils are weathered under conditions of high temperatures and humidity with well-defined alternating wet and dry seasons resulting in poor engineering properties such as high plasticity, poor workability, low strength, high permeability, tendency to retain moisture and high natural moisture content $[1,2,3]$. The effective use of these soils is therefore often hindered by difficulty in handling particularly under moist and wet conditions typical of tropical regions and can only be utilized after modification/stabilization. Lateritic soils that present such problems during construction processes are termed problematic laterites $[4,5]$. The modification/stabilization of engineering properties of soils is recognized by engineers as an important process of improving the performance of problematic soils and makes marginal soils perform better as a civil engineering material. The application of chemicals such as ordinary Portland cement, lime, fly ash etc. or a combination of these often results in the transformation of the soil index properties which may involve the cementation of the particles. Previously, the most commonly used additive for soil modification or stabilization is the ordinary Portland cement. But recent studies have shown that many of the soil problems can be ameliorated by the addition of pozzolanic fly ash [6, 7]. Experience with soils in the temperate zones revealed that compositional factors namely grain size distribution and plasticity characteristics exert significant influence on the engineering properties of soils [8]. Apart from assisting in the identification and classification of soils, they are indicators of problems in the fundamental properties of the soil such as compressibility, strength, permeability, swell potential and workability. Consequently, great importance is accorded to these properties when lateritic soil is been considered for a project [9]. In this regard, they are used to screen materials for various construction purposes. For example, percentage fines $\geq 30$, percentage clay $\geq 15$, liquid limit $\geq 20$, plasticity index $\geq 7$, is specified for liner and cover materials to be used in waste landfills [8], while for road bases, materials with percentage passing BS 200 sieve $>35 \%$, liquid limit $>35 \%$ and plasticity index $>12 \%$ are rejected without further investigation because such values give indication of poor and undesirable soil qualities for such purposes [10.11]. More so Soil stabilization refers to the procedure in which a special soil, a cementing material, or other chemical material is added to a natural soil to improve one or more of it properties'. One may achieve stabilization by mechanically mixing the natural soil and stabilizing material together so as to achieve a homogeneous mixture or by adding stabilizing material to an undisturbed soil deposit and obtaining interaction by letting it permeate through soil voids $[12,13]$ Where the soil and stabilizing agent are blended and worked together, the placement process usually includes compaction. Soil stabilizing additives are used to improve the properties of lessdesirable rood soils. When used these stabilizing agents can improve and maintain soil moisture content, increase soil particle cohesion and serve as cementing and water proofing agents [14]. A difficult problem in civil engineering works exists when the sub-grade is found to be clay soil. Soils having high clay content have the tendency to swell when their moisture content is allowed to increase [10, 15]. Many research have been done on the subject of soil stabilization using various additives, the most common methods of soil stabilization of clay soils in pavement work are cement and lime stabilization. The high strengths obtained from cement and lime stabilization may not always be required, however, and there is justification for seeking cheaper additives which may be used to alter the soil properties. 


\section{Materials and method}

This test was conducted in accordance with Bs 13771975 test 3. The plastic limit of a soil is the water content expressed as a percentage of the mass of the oven dried soil at the boundary between the plastic and semisolid states. The water content at this boundary is arbitrarily defined as the lowest water content at which the 5011 can be rolled into $3.0 \mathrm{~mm}$ diameter threads without breaking into pieces. The plastic limit was determined by measuring the water content of the soil when threads $3.0 \mathrm{~mm}$ diameter made from that particular soil just starts to crumble and can be taken as the smallest or minimum moisture content at which the soil can be rolled into $3.0 \mathrm{~mm}$ diameter thread without breaking up.

\section{Procedure}

About 50gm of laboratory air dried soil sample was ground to the consistency of powder and sieved with a sieve $(300 \mathrm{~mm}) .20 \mathrm{gm}$ of this sieved soil was then taken and mixed thoroughly with some quantity of distilled water with the aid of a spatula until it formed a ball. This soil bail was now placed on top of a flat glass plate and rolled continuously with the palm until 3.0mm soil threads was obtained. Part of this soil was then put into the oven for its moisture content to be determined. The process was repeated with further addition of sieved soil until the $3.0 \mathrm{~mm}$ diameter threads just starts to fumble. Part of this last soil and water mixture was removed and installed in the oven for is moisture content determination like for others. R plasticity index (P1) was calculated from the expression; P1 LL -PL, utilizing tile reading obtained after each water addition. The results generated from the experiments were subjected excel programs plotted each location result at the study area, the results plotted generated a model that that can be resolved to solve problem in other location were the experimental results are not available, finally the experimental values generated equations at different locations, this equation were resolved producing theoretical value empirically, the models value were compared with the experimental values from other locations in the study area.

\section{Results and discussion}

Table and figure on the comparison between theoretical and measured values are presented below.

Table 1: predictive values of plastic and liquid limits of soil at different depths

\begin{tabular}{ccc}
\hline Depth $(\mathbf{m})$ & plastic lime of soil & Liquid limit \\
\hline 0.2 & 24 & 32 \\
0.6 & 26 & 33 \\
0.8 & 26 & 34 \\
1 & 27 & 34 \\
1.2 & 29 & 42 \\
1.4 & 30 & 43 \\
1.6 & 30 & 46 \\
1.8 & 29 & 45 \\
2 & 31 & 45 \\
2.5 & 31 & 43 \\
4 & 32 & 43 \\
5
\end{tabular}

Table 2: predictive values of plastic and liquid limits of soil at different depths

\begin{tabular}{ccc}
\multicolumn{3}{c}{ Table 2: predictive values of plastic and liquid limits of soil at different depths } \\
\hline Depth (m) & plastic lime of soil & Liquid limit \\
\hline 0.2 & 21 & 30 \\
0.6 & 22 & 30 \\
0.8 & 25 & 31 \\
1 & 27 & 35 \\
1.2 & 28 & 39 \\
1.4 & 28 & 41 \\
1.6 & 29 & 43 \\
1.8 & 30 & 44 \\
2 & 31 & 44 \\
2.5 & 31 & 44 \\
4 & 32 & 45 \\
\hline
\end{tabular}


Table 3: predictive values of plastic and liquid limits of soil at different depths

\begin{tabular}{ccc}
\hline Depth $(\mathbf{m})$ & plastic lime of soil & Liquid limit \\
\hline 0.2 & 24 & 33 \\
0.6 & 24 & 34 \\
0.8 & 27 & 36 \\
1 & 29 & 41 \\
1.2 & 30 & 43 \\
1.4 & 30 & 43 \\
1.6 & 30 & 46 \\
1.8 & 31 & 46 \\
2 & 32 & 45 \\
2.5 & 30 & 44 \\
4 & 32 & 44 \\
\hline
\end{tabular}

Table 4: predictive values of plastic and liquid limits of soil at different depths

\begin{tabular}{ccc}
\hline Depth (m) & plastic lime of soil & Liquid limit \\
\hline 0.2 & 29 & 38 \\
0.6 & 29 & 38 \\
0.8 & 29 & 29 \\
1 & 27 & 38 \\
1.2 & 30 & 39 \\
1.4 & 31 & 43 \\
1.6 & 32 & 45 \\
1.8 & 32 \\
2.5 & 32 \\
4 & 32 \\
\hline
\end{tabular}

Table 5: predictive values of plastic and liquid limits of soil at different depths

\begin{tabular}{|c|c|c|}
\hline Depth (m) & plastic lime of soil & Liquid limit \\
\hline 0.2 & 19 & 28 \\
\hline 0.6 & 17 & 30 \\
\hline 0.8 & 18 & 30 \\
\hline 1 & 26 & 34 \\
\hline 1.2 & 27 & 34 \\
\hline 1.4 & 30 & 42 \\
\hline 1.6 & 31 & 41 \\
\hline 1.8 & 30 & 42 \\
\hline 2 & 30 & 42 \\
\hline 2.5 & 31 & 43 \\
\hline 3 & 31 & 43 \\
\hline 4 & 32 & 44 \\
\hline 5 & 32 & 44 \\
\hline
\end{tabular}




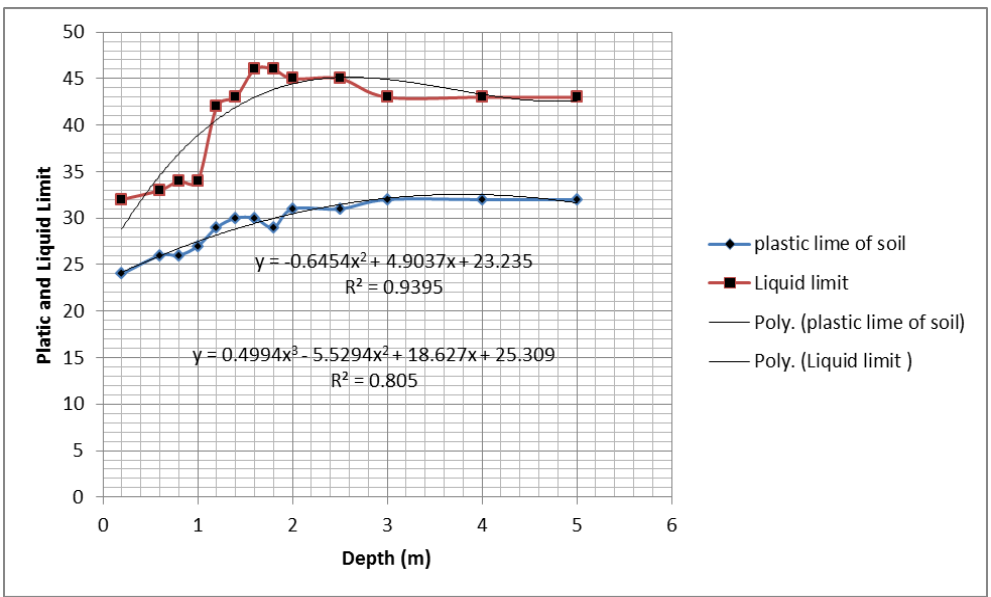

Figure 1: predictive values of plastic and liquid limits of soil at different depths

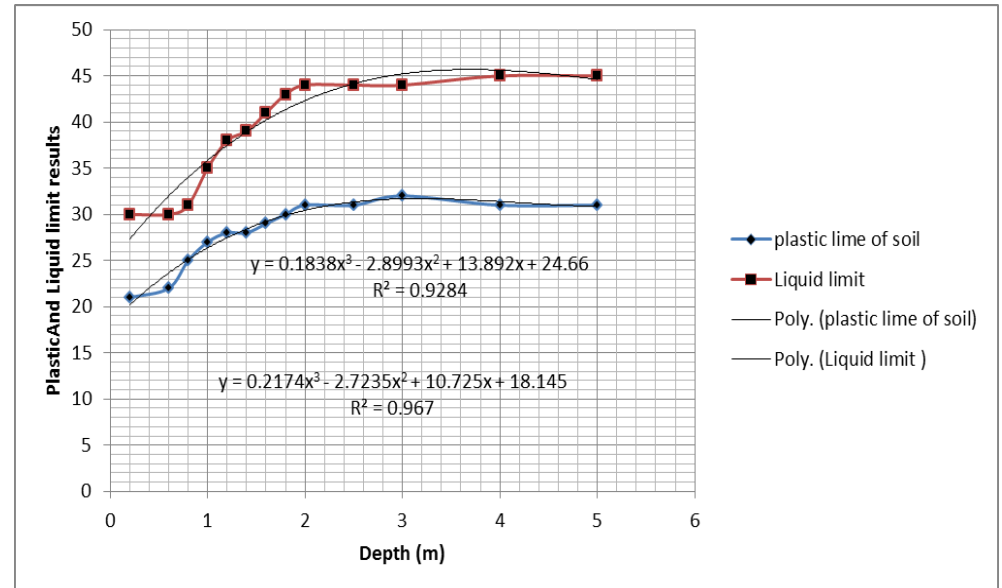

Figure 2: predictive values of plastic and liquid limits of soil at different depths

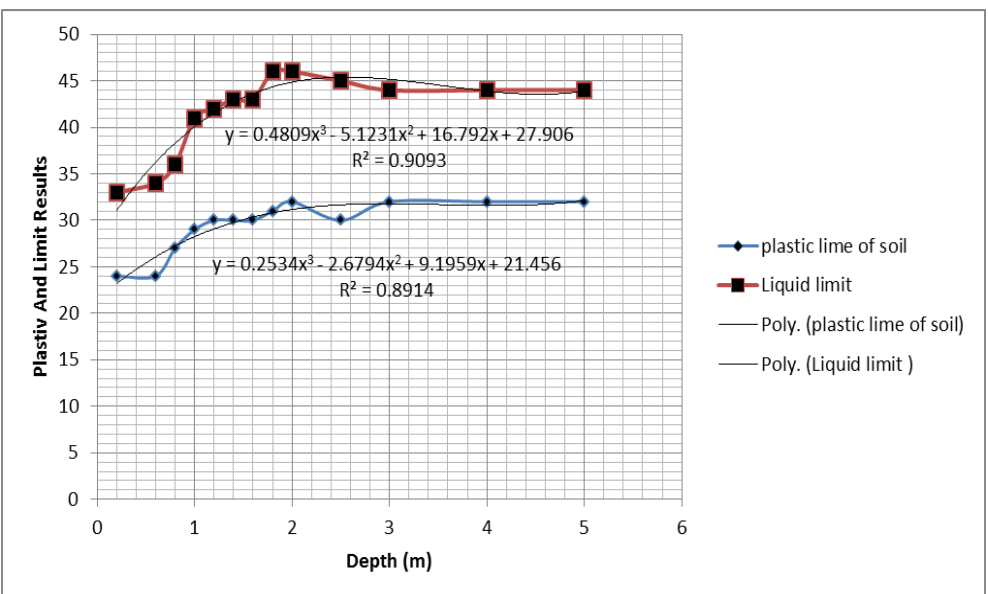

Figure 3: predictive values of plastic and liquid limits of soil at different depths 


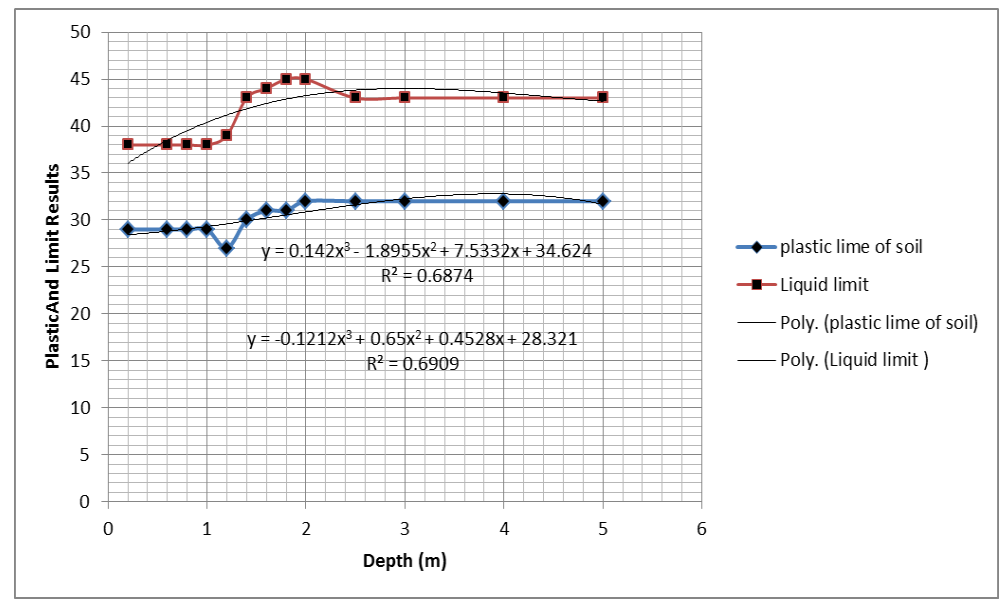

Figure 4: predictive values of plastic and liquid limits of soil at different depths

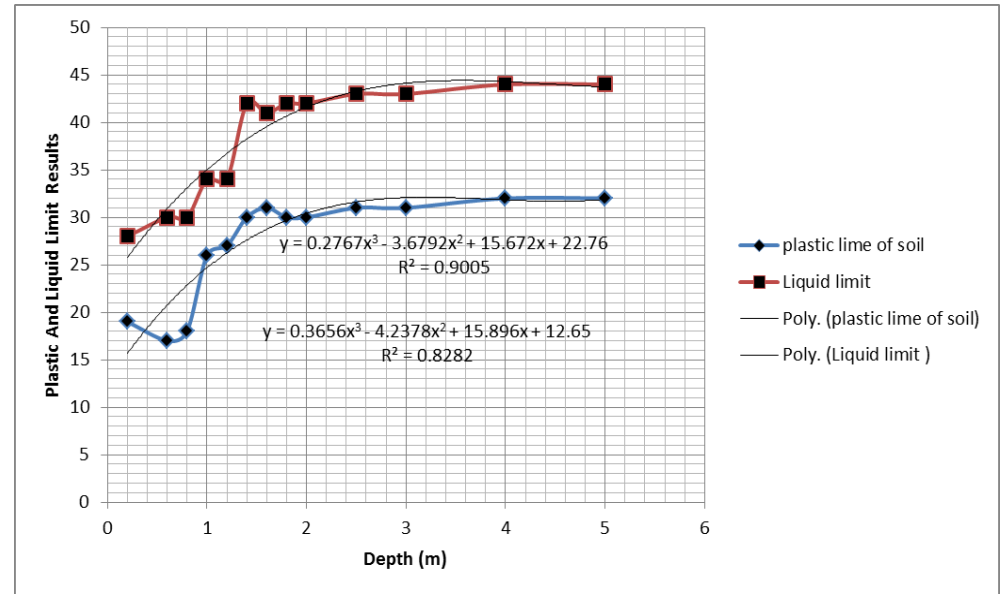

Figure 5: Predictive values of plastic and liquid limits of soil at different depths

Figure 1 shows that the liquid and plastic limit of soil that generate the classification of soil are of the same trend direction whereby the plastic limit generate its optimum value at $1.5 \mathrm{~m}$ and have slight variation, where it maintained a linear trend from 3-5m. Similarly, the liquid limit developed similar trend but the liquid have lower optimum values that deposits at $2 \mathrm{~m}$. It also has the same linear trend from 3-5m. Figure 2 maintained a gradual plastic limit from 0-1m rapidly increased from $1-2 \mathrm{~m}$ where the optimum values were recorded; developing slight variation from $3-5 \mathrm{~m}$ while that of liquid limit maintained the same trend, but its optimum value was recorded at $3 \mathrm{~m}$. Figure 3 , has a variation with a gradual increase from $0-2 \mathrm{~m}$, where an optimum value was recorded at $2 \mathrm{~m}$ maintaining a linear degree of liquid limit from $3-5 \mathrm{~m}$. Fluctuation was experienced from $0-2.5 \mathrm{~m}$, finally maintained a linear deposition from $3-5 \mathrm{~m}$. Figure 4 experienced a linear deposition of liquid limit from $0-1 \mathrm{~m}$, suddenly it experienced increased from $1.2-2 \mathrm{~m}$, slight decrease were observed between 2 and $3 \mathrm{~m}$ and finally maintaining linear trend from 3-5m while plastic limit of soil has a similar trend from 0-1m like liquid limit, suddenly it fluctuate between $1-2 \mathrm{~m}$. Linear trend were experienced from $3-5 \mathrm{~m}$. Figure 5 experienced vacillation on liquid limit; optimum values were recorded at $1.4 \mathrm{~m}$ and finally maintained a uniform liquid limit from $4-5 \mathrm{~m}$, while that of plastic limit generated oscillation from $0-3 \mathrm{~m}$ and finally developed uniformity from $4-5 \mathrm{~m}$. The models compared faviourably well with the experimental values, validation of this model with other experimental values implies that the model can be applied in design of flexible pavements The behaviour of plastic limit must be determined in order to avoid latitudinal deformation at wheel tract mainly associated with shoving along the road caused by heavy load, heavy tyre pressure and subjecting subgrade material to high stress. The study is imperative because the predictive values will definitely prevent the decrease of road life span caused by the negligence of not determining these fundamental parameters on soil for sub-base and subgrade. The sub-base materials are the foundation of the pavement system, whereby subgrades are subjected to lower stress. The combined thickness of sub base, base and surface must be great enough to reduce the stresses occurring in the subgrade values, which will not cause excessive destruction or displacement. Negligence of the foundation base during designs as factor of safety is one of the major cause of road failure in the study location. This condition has caused pavement distresses, i.e. damaging 
and deterioration of pavement through traffic load in most cases; it can also be traced to the sub base and sub grade, which is the foundation of the road. This is through excessive stress, and displacement of subgrade layers

\section{Conclusion}

The predictive model of plastic and liquid limit of soil has been developed; the model derived theoretical values through generated equations from the experimental values, the theoretical values were compared with other experimental values from other locations, both parameters compared faviourably. The validation of these models through other experimental result shows that the predictive model can be applied during design, the short live span of most roads in the deltaic environment is as a result to improper investigation of our soil for road construction in the deltaic environment. The foundations of road in the study area are the subgrade and sub base which are the earth material, the type of earth material in most part of the study area has high degree of plastic and liquid limits of soil, these are as a result of geological deposition of the soil structure. More so, our climate condition that generate high rain intensities cause high degree of saturation of the soil developing high liquid limit, this stated conditions are some of the factor why the predictive model should be applied in our road design and construction to increase the live span of the road in study area.

\section{References}

[1] Maigien R., Review of Research on Laterites. Natural Resources Research IV, United Nations Educational Scientific and Cultural Organization, 1966, Paris.

[2] Gidigasu M.D., Laterite Soil Engineering, Elsevier Scientific Publishing Co., 1976, New York.

[3] Chairman J.H., Laterite in Road Pavements. Construction Industry Research and Information Association (CIRCA), 1988, Special Publication 47, Westminster, London.

[4] Osula D.O.A., Lime modification of problem laterite, Engineering Geology, 1991, 30, p. 141-154.

[5] Oyediran A.T., Primary cause of highway failure in south-western Nigeria and lasting solution, Technical Transactions of the Nigerian Society of Engineers, 2001, 36(3), p. 54-60.

[6] Nilo C.C., Prietto P.D.M., Carraro J.A.H., Heineck K.S., Bahaviour of Compacted Soil - Fly ash - Carbide Lime Mixtures. J. Geotech. and Geoenv. Engrg. ASCE, 2001, 127(9), p. 774-782

[7] Osinubi K.J., Amadi A.A., Eberemu A.O., Shrinkage characteristics of compacted laterite soil - fly ash mixtures. NSE Technical Transaction, 2006, 41(1), p. 36-48.

[8] BRRI/Lyon Associates, Laterites and lateritic soils and other problem soils of Africa. An engineering study for USAID. AID/csd-2164, Baltimore, Md., 1971.

[9] Ola S.A., Geotechnical Properties and Behavior of some Nigerian Lateritic soils, In: Tropical Soils of Nigeria in Engineering Practice, Ed. A. Ola Balkema, Rotterdam, 1983. Benson C.H.

[10] Zhai H., Wang X., Estimating hydraulic conductivity of compacted clayliners, J. Geotech Engrg ASCE, 1994, 120(2), p. 366-387.

[11] Nigerian General Specification for Roads and Bridges, Federal Ministry of Works and Housing, Abuja, Nigeria, 1997.

[12] Dallas N. L Syam N: Recommended Practice for Stabilization of Subgrade Soils and Base Materials Texas Transportation Institute 2009 Texas A\&M University College station, Texas.

[13] Perloff, W. H. (1976). Soil Mechanics, Principals and Applications. New York: John Wiley \& Sons.

[14] Janathan Q. Addo, Sanders, T. G. \& Chenard, M. Road dust suppression :Effect on unpaved Road Stabilization 2004.

[15] Chen, F. H. Foundations on Expansive Soils. Amsterdam:1981 Elsevier Scientific Publishing Company. 